Plant Tissue Cult. \& Biotech. 23(1): 1-10, 2013 (June)

$\overline{\text { PTC\&B }}$

\title{
Application of Cobalt Chloride and Silver Nitrate for Efficient Microspore Culture of Brassica rapa ssp.
}

\author{
Khandakar Md. Rayhanul Kabir, Soon-Wook Kwon"1, and Yong- \\ Jin Park ${ }^{1 *}$ \\ Department of Plant Resources, College of Industrial Sciences, Kongju National \\ University, Yesan 340-702, Republic of Korea
}

Key words: Microspore embryogenesis, Inhibitors of ethylene, Embryo yields

\begin{abstract}
The effects of ethylene antagonistic cobalt chloride and silver nitrate, on microspore embryogenesis were investigated using three different concentrations in the medium for three Korean cultivars (two non-heading and one heading) of Brassica rapa ssp. Inclusion of cobalt chloride $(5 \mu \mathrm{M})$ in the culture medium significantly improved embryo production in the non-heading cultivar (33 embryos/bud) with embryo yields being increased up to $32 \%$. The addition of silver nitrate $(0.1 \mathrm{mg} / \mathrm{l})$ to the culture medium also showed a progressive increase in embryo yields in the non-heading cultivar (34 embryos/bud) with embryo yields being increased up to $36 \%$. For the heading cultivars, the highest embryogenic response was 2.8 embryos/bud (Jo saeng Miho), following the addition of silver nitrate $(0.1 \mathrm{mg} / \mathrm{l})$ to the culture medium, whereas 2.4 embryos/bud were observed with the addition of $5 \mu \mathrm{M}$ cobalt chloride to the culture medium.
\end{abstract}

\section{Introduction}

Isolated microspore culture is well-known for its potential applications in plant genetic research and breeding programs. Over the past few years, numerous reports on isolated microspore culture have been focused on Brassica species and among those Chinese cabbage - Brassica rapa or Brassica campestris varieties are included. The addition of activated charcoal (AC) into the culture medium can induce high-frequency microspore embryogenesis (Dias 1999, Prem et al. 2008) and $A C$ is often used for microspore culture of Chinese cabbage (Gu et al. 2003,

*Author for correspondence: <yjpark@kongju.ac.kr>. ${ }^{1}$ Legume Bio-Resource Center of Green Manure (LBRCGM), Kongju National University, Yesan 340-702, Republic of Korea. 
Wang et al. 2004, Wang et al. 2009, Na et al. 2009, Zhang et al. 2012). Wang et al. (2004) found that microspore embryogenesis of Chinese cabbage was enhanced by the addition of activated charcoal, but the response was genotype-dependent. Inclusion of ethylene antagonistic silver nitrate $\left(\mathrm{AgNO}_{3}\right)$ in the culture medium for anther and microspore cultures of different Brassica ssp. has been reported to significantly increase androgenesis (Dias and Martins 1999, Malik et al. 2001, Achar 2002, Prem et al. 2005, Prem et al. 2008, Na et al. 2009, Na et al. 2011). Other inhibitors of ethylene production and action such as aminoethoxyvinylglycine (AVG), cobalt chloride $\left(\mathrm{CoCl}_{2}\right)$ and silver thiosulphate have a significant role in embryo development and maturation (Hays et al. 2000). In an experiment on isolated microspore culture of B. napus, Leroux et al. (2009) reported that isolated microspores, subjected to an initial heat stress in a medium supplemented with inhibitors of ethylene synthesis such as $\mathrm{CoCl}_{2}$, exhibited significantly increased embryo yields.

In the present study, three different concentrations of $\mathrm{CoCl}_{2}$ were applied to a microspore culture of Chinese cabbage (B. rapa ssp.) and at the same time three different concentrations of $\mathrm{AgNO}_{3}$ were also applied in order to enhance the microspore embryogenesis.

\section{Materials and Methods}

Three local cultivars of B. rapa ssp., heading type (have broad green leaves tightly wrapped in a cylindrical formation and usually forming a compact head) Korean cultivars: "Jo saeng Miho" and "Gang dong Soggeum", and non-heading type (do not form heads; instead, they have smooth, dark green leaf blades forming a cluster) Korean cultivar: "Seoul baechu" were tested as donor plants. Vernalized (conducted at the four - five-leaf stage for 4 weeks at $5^{\circ} \mathrm{C}$ ) plants were grown under a $16 \mathrm{hrs}$ photoperiod, a day/night temperature of $20 / 15^{\circ} \mathrm{C}$, and with a high nutritive status. Ten plants were grown for each genotype. A few days prior to flower bud collection the temperature was adjusted to $12 / 10^{\circ} \mathrm{C}$ (day/night regime).

The microspore isolation procedure was based on that of Wang et al. (2009) with some modifications. Flower buds comprising microspores at the late uninucleate and early binucleate stage were selected (buds were typically $2.5 \mathrm{~mm}$ in length). The media were sterilized by filtration through membrane filters of successive pore size $0.22 \mu \mathrm{m}$, and the $\mathrm{pH}$ values were adjusted to $5.8-6.0$. The buds were surface sterilized in $1 \%$ sodium hypochlorite for $18 \mathrm{~min}$ prior to washing three times with sterile distilled water. The buds were then macerated in B5 medium (Gamborg et al. 1968, provided by Duchefa Biochemie, 
Netherlands) containing 13\% (w/v) sucrose, $\mathrm{pH} 6.0$ (B5-13). The suspension was filtered through $45 \mu \mathrm{m}$ nylon mesh to a final volume of $10 \mathrm{ml}$ in a centrifuge tube. The filtrates were centrifuged at $1000 \mathrm{rpm}$ for $3 \mathrm{~min}$. The pellet was resuspended in $10 \mathrm{ml}$ of $\mathrm{B} 5-13$ and this procedure was repeated twice.

The final pellet was resuspended in the microspore culture medium. Halfstrength NLN medium (Lichter 1982; provided by Duchefa Biochemie, Netherlands) containing $10 \%(\mathrm{w} / \mathrm{v})$ sucrose with addition of a half-strength of microelements ( $\mathrm{Na}$ et al. 2009) was used as the control medium and this medium with different concentrations of $\mathrm{CoCl}_{2}(2.5,5,7.5 \mu \mathrm{M})$ and $\mathrm{AgNO}_{3}(0.1,0.5,0.75$ $\mathrm{mg} / \mathrm{l}$ ) was used for the treatments ( $\mathrm{pH} 5.8$ for every treatment). AC (an autoclaved suspension of $1 \mathrm{~g}$ activated charcoal, $0.5 \mathrm{~g}$ agarose and $100 \mathrm{ml}$ double distilled water; Gland et al. 1988) was added to the medium of microspore culture $(100 \mu \mathrm{l}$ of activated charcoal suspension/Petri dish). The microspore suspension was dispensed into $60 \mathrm{~mm} \times 15 \mathrm{~mm}$ Petri dishes using $3 \mathrm{ml}$ per plate and one flower bud per Petri dish were remain. The Petri dishes were sealed with double layers of Parafilm, incubated in the dark for an initial period of 24 hrs at $32.5^{\circ} \mathrm{C}$ and then incubated at $24^{\circ} \mathrm{C}$ in the dark. The embryos were visible after 11 - 14 days and then the Petri dishes were transferred to a slow rotary shaker $(60 \mathrm{rpm})$ under a $16 \mathrm{hrs}$ photoperiod $\left(50 \mu \mathrm{mol} / \mathrm{m}^{2} / \mathrm{s}\right)$ at $24^{\circ} \mathrm{C}$ until the embryos became green ( $\mathrm{Na}$ et al. 2011). Each treatment was carried out with three replications (100 flower buds were considered for one replication) and the results were quantified in terms of the number of normal embryos produced per bud. Means of the three replications based on LSD at $0.05 \%$ level.

\section{Results and Discussion}

Under present experimental conditions, the non-heading cultivar "Seoul baechu" exhibited an extremely high embryogenic ability, whereas the other two heading cultivars exhibited very low embryogenic ability. Among the two heading cultivars, "Jo saeng Miho" exhibited a slightly higher embryogenic response than "Gang dong Soggeum." An increase in embryo production was achieved with the addition of $0.1 \mathrm{mg} / \mathrm{l} \mathrm{AgNO}_{3}$ into the medium for all genotypes (Table 1), but most significantly in the non-heading "Seoul baechu" (Fig. 1). The mean number of embryos increased from 25 - 34 per bud for "Seoul baechu," 2.1 - 2.8 per bud for "Jo saeng Miho," and 1.1 - 1.4 per bud for "Gang dong Soggeum" at this concentration. However, when the medium was supplemented with $0.5 \mathrm{mg} / \mathrm{l}$ $\mathrm{AgNO}_{3}$, the frequency of embryogenesis decreased to 31 embryos/bud, 2.5 embryos/bud, and 1.21 embryos/bud for "Seoul baechu," "Jo saeng Miho," and "Gang dong Soggeum," respectively. These values were still higher than the 
control. A further increase in $\mathrm{AgNO}_{3}$ concentration further decreased the embryo yields.

For $\mathrm{CoC}_{2}$, all three concentrations $(2.5,5$, and $7.5 \mu \mathrm{M})$ tested were found to be effective when added into the culture media. The medium supplemented with $5 \mu \mathrm{M} \mathrm{CoC1} 1_{2}$ showed the highest response: the mean numbers of embryos were 33 embryos/bud, 2.47 embryos/per bud, and 1.25 embryos/bud for "Seoul baechu," "Jo saeng Miho," and "Gang dong Soggeum," respectively (Table 2). The medium supplemented with $2.5 \mu \mathrm{M} \mathrm{CoC} 1_{2}$ resulted in production of 27 embryos/bud and 2.22 embryos/bud for "Seoul baechu" and "Jo saeng Miho," respectively. The medium supplemented with $7.5 \mu \mathrm{M} \mathrm{CoC1} 1_{2}$ resulted in production of $28 \mathrm{embryos} / \mathrm{bud}, 2.25 \mathrm{embryos} / \mathrm{bud}$, and $1.21 \mathrm{embryos} / \mathrm{bud}$ for "Seoul baechu," "Jo saeng Miho," and "Gang dong Soggeum," respectively.

Table 1. Effects of $\mathrm{AgNO}_{3}$ on formation of microspore embryo of B. rapa ssp.

\begin{tabular}{cccc}
\hline \multirow{2}{*}{$\begin{array}{c}\mathrm{AgNO}_{3} \text { concentration } \\
(\mathrm{mg} / \mathrm{l})\end{array}$} & \multicolumn{2}{c}{ Mean no. of normal embryos/bud $( \pm \mathrm{Sd})$} \\
\cline { 2 - 4 } & $\begin{array}{c}\text { Jo saeng } \\
\text { Miho }\end{array}$ & $\begin{array}{c}\text { Gang dong } \\
\text { Soggeum }\end{array}$ & $\begin{array}{c}\text { Seoul } \\
\text { baechu }\end{array}$ \\
\hline 0.0 & $2.11 \pm 0.22 \mathrm{bc}$ & $1.11 \pm 0.10 \mathrm{~b}$ & $25.06 \pm 0.09 \mathrm{c}$ \\
0.1 & $2.80 \pm 0.23 \mathrm{a}$ & $1.40 \pm 0.10 \mathrm{a}$ & $34.00 \pm 1.40 \mathrm{a}$ \\
0.5 & $2.50 \pm 0.08 \mathrm{ab}$ & $1.21 \pm 0.07 \mathrm{ab}$ & $31.00 \pm 1.00 \mathrm{~b}$ \\
0.75 & $2.00 \pm 0.25 \mathrm{c}$ & $0.97 \pm 0.22 \mathrm{~b}$ & $22.00 \pm 1.00 \mathrm{~d}$ \\
\hline
\end{tabular}

Means \pm Sd were calculated from three replicates. Means in a column sharing the same letter are not significantly different at the $5 \%$ level.

Table 2. Effects of additional $\mathrm{CoCl}_{2}$ on formation of microspore embryo of $\mathrm{B}$. rapa ssp.

\begin{tabular}{cccc}
\hline \multirow{2}{*}{$\begin{array}{c}\text { Additional } \mathrm{CoCl}_{2} \\
(\mu \mathrm{M})\end{array}$} & \multicolumn{3}{c}{ Mean no. of normal embryos/bud $( \pm \mathrm{Sd})$} \\
\cline { 2 - 4 } & Jo saeng Miho & Gang dong Soggeum & Seoul baechu \\
\hline 0.0 & $2.11 \pm 0.22 \mathrm{~b}$ & $1.11 \pm 0.10 \mathrm{a}$ & $25.06 \pm 0.09 \mathrm{c}$ \\
2.5 & $2.22 \pm 0.22 \mathrm{ab}$ & $1.12 \pm 0.12 \mathrm{a}$ & $27.04 \pm 1.10 \mathrm{~b}$ \\
5 & $2.47 \pm 0.10 \mathrm{a}$ & $1.25 \pm 0.08 \mathrm{a}$ & $33.00 \pm 1.35 \mathrm{a}$ \\
7.5 & $2.25 \pm 0.16 \mathrm{ab}$ & $1.21 \pm 0.07 \mathrm{a}$ & $28.00 \pm 1.16 \mathrm{~b}$ \\
\hline
\end{tabular}

Means \pm Sd were calculated from three replicates. Means in a column sharing the same letter are not significantly different at the $5 \%$ level.

It was observed that for both $\mathrm{AgNO}_{3}$ and $\mathrm{CoCl}_{2}$, a particular concentration in the medium was not equally effective for all cultivars. For all three cultivars, the use of $5 \mu \mathrm{M} \mathrm{CoCl}_{2}$ was slightly inferior to the use of $0.1 \mathrm{mg} / \mathrm{AgNO}_{3}$.

Fully developed dicotyledonous embryos (Fig. 2) were cultured in a germination medium: solid hormone-free MS supplemented with 3\% sucrose 
and solidified with $2.5 \mathrm{~g} / \mathrm{l}$ Gelrite, at $22^{\circ} \mathrm{C}$ with a $14 \mathrm{hrs}$ photoperiod (300 $\mu \mathrm{mol} / \mathrm{m}^{2} / \mathrm{s}$ ) (Fig. 3A). Developed plantlets were acclimated in a nursing room and after two weeks, they were transferred to soil for further growth (Fig. 3B, C). Microspore derived plants were growing typically in the soil.

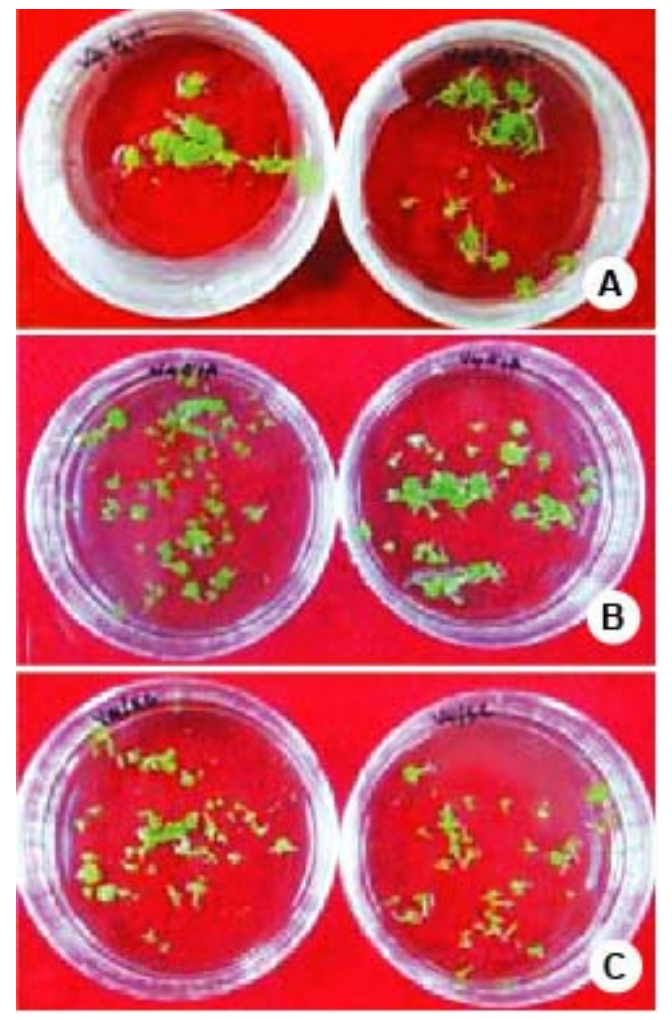

Fig. 1. Microspore culture of B. rapa ssp.: (A) Fully developed embryos of "Seoul baechu" in liquid medium three weeks after microspore isolation. (B) Embryos of "Seoul baechu" in medium containing $0.1 \mathrm{mg} / \mathrm{l} \mathrm{AgNO}_{3}$. (C) Embryos of "Seoul baechu" in medium containing additional $5 \mu \mathrm{M} \mathrm{CoCl} 2$.

Silver nitrate $\left(\mathrm{AgNO}_{3}\right)$ is known to be a potent inhibitor of ethylene action in plants (Beyer 1976, Veen and Overbeek 1989) and is widely used in plant tissue culture and somatic embryogenesis (Kumar et al. 2009). The addition of $\mathrm{AgNO}_{3}$ to anther culture media has been reported to significantly promote embryo production in different Brassica species (Biddington et al. 1988, Ockendon and McClenagham 1993, Dias and Martins 1999, Achar 2002). A significant synergistic effect of $\mathrm{AgNO}_{3}$ in the isolated microspore culture of Brassica was reported for the first time by Prem et al. (2005). The addition of AC in medium containing $10 \mu \mathrm{M} \mathrm{AgNO}$ resulted in a fourfold increase in microspore 
embryogenesis of $B$. juncea (Prem et al. 2008). In another experiment, when 0.1 $\mathrm{mg} / \mathrm{l} \mathrm{AgNO}_{3}$ was added to the half strength modified NLN medium with $\mathrm{AC}$, the number of microspore-derived embryos significantly increased in Broccoli (Brassica oleracea L. var. italica) ( $\mathrm{Na}$ et al. 2011). In the present experiment, when $\mathrm{AgNO}_{3}$ was added to the culture medium at three different concentrations, 0.1 $\mathrm{mg} / \mathrm{l}$ was found to produce maximum embryogenic yield. At that concentration the rate of embryo formation was increased by 36\% in non-heading "Seoul baechu," 33\% in "Jo saeng Miho," and 27\% in "Gang dong Soggeum."

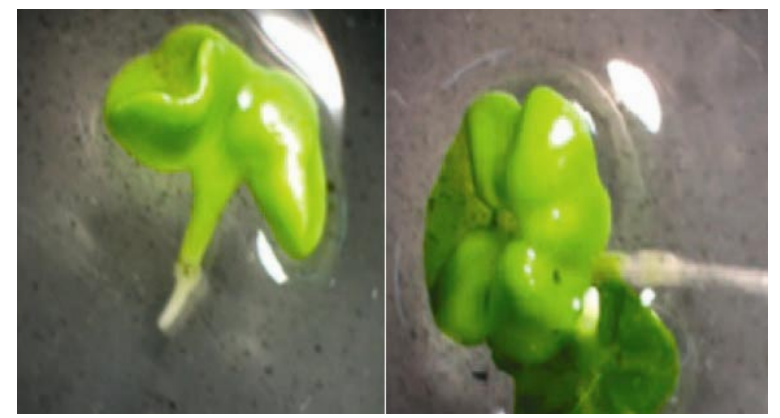

Fig. 2. Fully developed dicotyledonous embryos of B. rapa ssp. $(\times 20)$

Cobalt and nickel ions are inhibitors of ethylene biosynthesis (Lau and Yang 1976) and they have been reported to inhibit the enzymatic conversion of 1-aminocyclopropane-1-carboxylic acid (ACC) to ethylene in a variety of plant systems (Yang and Hoffman 1984). $\mathrm{CoCl}_{2}$ inhibits ethylene production by blocking the conversion of ACC to ethylene and was used for the stimulation of somatic embryogenesis in Daucus carota, which showed an enhanced ability to develop embryos (Roustan et al. 1989). In some cases, $\mathrm{CoCl}_{2}$ was equally effective as $\mathrm{AgNO}_{3}$ for inducing morphogenesis (Chraibi et al. 1991). In an experiment, $\mathrm{CoC}_{2}$ increased cotyledon shoot regeneration in $B$. campestris tissue culture, but was inferior to $\mathrm{AgNO}_{3}$ (Palmer 1992). Leroux et al. (2009) reported an efficient isolated microspore culture of $B$. napus following $\mathrm{CoCl}_{2}$ treatment, with embryo yields being significantly increased by up to $75 \%$. In their experiment, effective concentrations ranged from $2.5-10 \mu \mathrm{M}$, while the most responsive concentration was $5 \mu \mathrm{M}$ and the addition of $\mathrm{CoCl}_{2}$ before or just after heat treatment greatly increased embryo yields. In present study, when $\mathrm{CoCl}_{2}$ was added to the culture medium, all of the concentrations tested resulted in an increased embryogenic yield, but $5 \mu \mathrm{M}$ was found to be the optimum concentration with embryo yields being significantly increased by $32 \%$ for nonheading "Seoul baechu". This concentration in the medium was not such effective for the other two heading cultivars $(18 \%$ increase in embryogenic yield 
for "Jo saeng Miho" and 13\% increase for "Gang dong Soggeum"). Although our current study partially supported two previous experiments ( $\mathrm{Na}$ et al. 2009, Leroux et al. 2009), further investigations for a wide range of varieties and treatments with the detection of limited variation from the sources should be considered. When the two chemicals were utilized together at their lowest active concentrations $\left(0.1 \mathrm{mg} / \mathrm{l} \mathrm{AgNO}_{3}+5 \mu \mathrm{M} \mathrm{CoCl}_{2}\right)$, the embryo yields decreased in comparison with control cultures (data not shown).

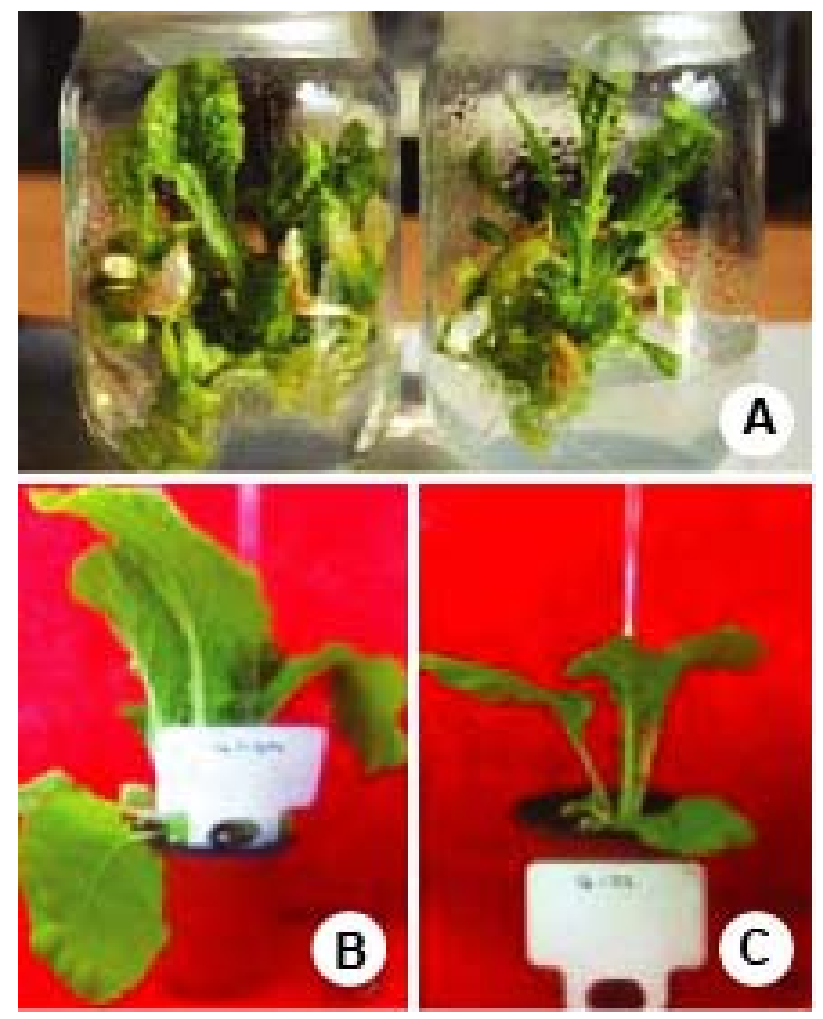

Fig. 3. (A) Regenerating plants from dicotyledonary embryos. (B) A plant, regenerated from an embryo of the medium containing $0.1 \mathrm{mg} / \mathrm{AgNO}$, transplanted from the glass jar to soil. (C) A plant, regenerated from an embryo of the medium containing $5 \mu \mathrm{M}$ $\mathrm{CoCl}_{2}$, transplanted from the glass jar to soil.

The success of microspore culture critically depends on a number of intrinsic and extrinsic factors and many studies have focused on increasing the frequency of embryogenesis for responsive species and on developing protocols, which have been summarized in review articles (Maluszynski et al. 2003, Babbar et al. 2004, Ferrie and Caswell 2011). New and improved methods using developed 
technologies for isolated microspore culture could help to improve valuable crops such as Chinese cabbage.

\section{Acknowledgements}

This work was supported by a grant from the BioGreen 21 Program (No. PJ009039), Rural Development Administration, Republic of Korea.

\section{References}

Achar PN (2002) A study of factors affecting embryo yields from anther culture of cabbage. Plant Cell Tiss. Org. Cult. 69: 183-188.

Babbar SB, Agarwal PK, Sahay S and Bhojwani SS (2004) Isolated microspore culture of Brassica: An experimental tool for developmental studies and crop improvement. Indian J. Biotechnol. 3: 185-202.

Beyer EM (1976) A potent inhibitor of ethylene action in plants. Plant Physiol. 58: 268-271.

Biddington NL, Sutherland RA and Robinson HT (1988) Silver nitrate increases embryo production in anther culture of Brussels sprouts. Ann. Bot. 62: 181-185.

Chraibi BKM, Latche A, Raustan JP and Fallot J (1991) Stimulation of shoot regeneration from cotyledons of Helianthus annuus by ethylene inhibitors silver and cobalt. Plant Cell Rep. 10: 204-207.

Dias JCS (1999) Effect of activated charcoal on Brassica oleracea microspore culture embryogenesis. Euphytica 108: 65-69.

Dias JCS and Martins MG (1999) Effect of silver nitrate on anther culture embryo production of different Brassica oleracea morphotypes. Sci. Hort-Amsterdam. 82: 299-307.

Ferrie AMR and Caswell KL (2011) Isolated microspore culture techniques and recent progress for haploid and doubled haploid plant production. Plant Cell Tiss. Org. Cult. 104: 301-309.

Gamborg OL, Miller RA and Ojima K (1968) Nutrient requirements of suspension cultures of soybean root cells. Exp. Cell. Res. 50: 151-158.

Gland A, Lichter R and Schweiger HG (1988) Genetic and exogenous factors affecting embryogenesis in isolated microspore cultures of Brassica napus L. J. Plant Physiol. 132: 613-617.

Gu HH, Zhou WJ and Hagberg P (2003) High frequency spontaneous production of doubled haploid plants in microspore cultures of Brassica rapa ssp. var. chinensis. Euphytica 134: 239-245.

Hays DB, Reid DM, Yeung EC and Pharis RP (2000) Role of ethylene in cotyledon development of microspore derived embryos of Brassica napus. J. Exp. Biol. 51: 1851-1859. 
Kumar V, Parvatam G and Ravishankar GA (2009) $\mathrm{AgNO}_{3}$ - A potential regulator of ethylene activity and plant growth modulator. Electron. J. Biotechnol. 12: 1-15.

Lau OL and Yang SF (1976) Inhibition of ethylene production by cobaltous ion. Plant Physiol. 58: 114-117.

Leroux B, Carmoy N, Giraudet D, Potin P, Larher F and Bodin M (2009) Inhibition of ethylene biosynthesis enhances embryogenesis of cultured microspores of Brassica napus. Plant Biotechnol. Rep. 3: 347-353.

Lichter R (1982) Induction of haploid plants from isolated pollen of Brassica napus. Plant Breed. 105: 427-434.

Malik MR, Rangaswamy NS and Shivanna KR (2001) Induction of microspore embryos in a CMS line of Brassica juncea and formation of the androgenic plantlets. Euphytica 120: 195-203.

Maluszynski M, Kasha KJ, Forster BP and Szarejko I (2003) Doubled haploid production in crop plants: a manual. Kluwer Academic Publisher, Dordrecht.

Na HY, Park JH and Chun CH (2011) The effects of plant growth regulators, activated charcoal, and $\mathrm{AgNO}_{3}$ on microspore derived embryo formation in broccoli (Brassica oleracea L. var. italica). Hort. Environ. Biotechnol. 52(5): 524-529.

Na HY, Park SY, Hwang GY, Yoon MK and Chun CH (2009) Medium, AgNO3, activated charcoal and NAA effects on microspore culture in Brassica rapa. Kor. J. Hort. Sci. Technol. 27: 657-661 (in Korean with English summary).

Ockendon DJ and McClenaghan R (1993) Effect of silver nitrate and 2, 4-D on anther culture of Brussels sprouts (Brassica oleracea var. gemmifera). Plant Cell Tiss. Org. Cult. 32: $41-46$.

Palmer CE (1992) Enhanced shoot regeneration from Brassica campestris by silver nitrate. Plant Cell Rep. 11: 541-545.

Prem D, Gupta K and Agnihotri A (2005) Effect of various exogenous and endogenous factors on microspore embryogenesis in Indian mustard, Brassica juncea L. Czern \& Coss). In Vitro Cell. Dev. Biol. Plant. 41: 266-273.

Prem D, Gupta K, Gautam S and Agnihotri A (2008) Activated charcoal induced high frequency microspore embryogenesis and efficient doubled haploid production in Brassica. Plant Cell Tiss. Org. Cult. 93: 269-282.

Roustan JP, Latche A and Fallot J (1989) Stimulation of Daucus carota somatic embryogenesis by inhibitors of ethylene synthesis: Cobalt and nickel. Plant Cell Rep. 8: 182-185.

Veen H and Overbeek JHM (1989) The action of silver thiosulfate in carnation petals. In: Clijsters $H$, de Proft $M$, Marcelle R, van Poucke M (eds) Biochemical and Physiological Aspects of Ethylene Production in Lower and Higher Plants. Kluwer Academic Publishers, Dordrecht.

Wang TT, Li HX, Zhang JH, Lu YE and Ye ZB (2004) Isolated microspore culture and plant regeneration in purple flowering stalk (Brassica campestris ssp. chinensis var. purpurea Hort.). J. Wuhan Bot. Res. 22: 569-571 (in Chinese with English summary). 
Wang TT, Li HX, Zhang JH, Ouyang B, Lu YG and Ye ZB (2009) Initiation and development of microspore embryogenesis in recalcitrant purple flowering stalk (Brassica campestris ssp. chinensis var. purpurea Hort.). Sci. Hortic-Amsterdam 121: 419-424.

Yang SF and Hoffman NE (1984) Ethylene biosynthesis and its regulation in higher plants. Ann. Rev. Plant Physiol. 35: 155-189.

Zhang Y, Wang AJ, Liu Y, Wang YS and Hui F (2012) Improved production of doubled haploids in Brassica rapa through microspore culture. Plant Breed. 131: 164-169. 